\title{
EMULATION OF HUMAN ATTENTION FOR EXPLORATION OF VIRTUAL ARCHITECTURAL ENVIRONMENTS. APPLICATION TO LE CORBUSIER'S PROMENADE ARCHITECTURALE OF A VIRTUAL VILLE SAVOYE
}

\author{
Viviana Barneche-Naya and Luis A. Hernández-Ibáñez \\ Universidade da Coruña, Spain
}

\begin{abstract}
This paper describes the use of Paseante, an autonomous agent for real-time assisted navigation inside virtual environments. In order to carry out its implementation, theories of human attention and environmental psychology were considered. This work describes the application of the system for the emulation of one of the mythical experiences of the theory and history of Architecture: La Promenade Architecturale inside the Ville Savoye.
\end{abstract}

\section{KEYWORDS}

Human Computer Interaction, Human Attention, Aided Navigation, Real-time Visualization, Architectural Visualization

\section{INTRODUCTION}

For some years, real-time technologies for architectural visualization have been used, mainly motivated by the possibility of traveling and interacting with the virtual environment. Every day real-time simulations acquire a greater realism, however, natural navigation forms are still lacking, closer to human movement than to the mechanical sequence of turns and movements, which characterize current forms of movement.

Research conducted on navigation has found strong correlations between real-world and virtual navigation (Richardson et al, 1999; Gaunet et al, 2001; Claessen et al, 2016) which has led to virtual environments being used to investigate spatial cognition in simulated real environments. This has been applied to particular cases such as Alzheimer's, people with brain injury or orientation activities in elderly people (Foreman et al, 2005; Plancher et al, 2012; Cogné et al, 2017).

A detected deficiency arises in the navigation of non-expert users in virtual environments since their attention is focused in the first instance on learning the maneuvers of navigation itself (Waller, 2000; Smith \& Du'Mont, 2009). This greatly affects their ability to understand what you are seeing; so many inexperienced visitors may feel somewhat lost or not be very clear what to do or where to look. Because of this, it was necessary to first identify what are the elements that define the experience of navigation in the real architectural space. This research analyzed what aspects related to human perception and attention affect the ways of navigation of human beings within the built environment in real life.

\section{METHODOLOGY}

The implementation of this system has required the creation of an autonomous agent endowed with criteria to obtain the most interesting point of attention for each position and visual orientation of the user in the virtual environment. For this, it was necessary to enter into the analysis of human perception of space.

Lewin's field theory (Lewin, 1938) was considered in the first place. It explains human movement in an environment in terms of forces acting on it from different directions and with different intensities. The work 
also considers the affordance theory (Gibson, 1979), which describes the potential capacity of any element of the environment to attract attention and be used by the perceiver. The system also implements the concept of attentional focus, especially the metaphor of the focus of light (Posner et al, 1985) and the metaphor of the attentional gradient as a variation of assigned resources in the visual field as a function of the origin position of the gradient (LaBerge \& Brown, 1989).

Related to the navigation design, two concepts were considered: the attentional value of the reference points according to their visual, cognitive and structural characteristics (Sorrows \& Hirtle, 1999) and the concept of enriched space (Raubal \& Winter, 2002). The system is implemented as an autonomous agent inside the character representing the user in the Unreal Engine 4 game engine. This agent subtly modifies the view and movement direction based on the presence of attracting elements in the scene.

On a given environment, the analysis of the presence of landmarks in a zone surrounding the user can be used to model the amount of attention that the area that contains every element may arise from the user.

We have implemented this by designing an element that can be placed anywhere in the virtual model called attractor. This element is defined by several parameters that include interest, range of attraction, decay and other variables that describe the willingness to look at it based on the distance to the user and direction in the scene relative to the character's sight direction.

The presence of several attractors in the viewable area surrounding the user can be weighted using models from the field of Psychology of Perception such as the one proposed by Lewin. This model defines a hodological space (the space surrounding the user that contains zones that push or pull his or her attention based on personal interest related to each one). In Lewin's model, every area has a valence that quantifies the attractive effect to the user.

The resultant of all forces of attraction describes the final intention of the subject to point his or her attention to a particular direction. Our solution, as described in figure 1, weights the attracting forces by turning the continuous Lewin's space into a discrete one, populated with attractors (A) with given interests, and considering every attractor as generator of a field of attractive force, being the geometry of this field a function that involves distance, direction relative to user's sight and two values of willingness for distance and angle (q). Then, a vector of attention of this attractor $\left(\mathbf{F}_{\mathrm{A}}\right)$ is defined, being the valence the value of its module.

The center of attention $(\mathbf{C})$ is then calculated as a center of force, and will be used to drive smoothly the user sight toward it when no turning input is detected in a given time. By placing attractors in every interesting point, the movement of the user can be controlled. Interest of attractors can decay with exposure to the user contemplation. The center of attention is being recalculated every frame considering the change in location and orientation of the user.
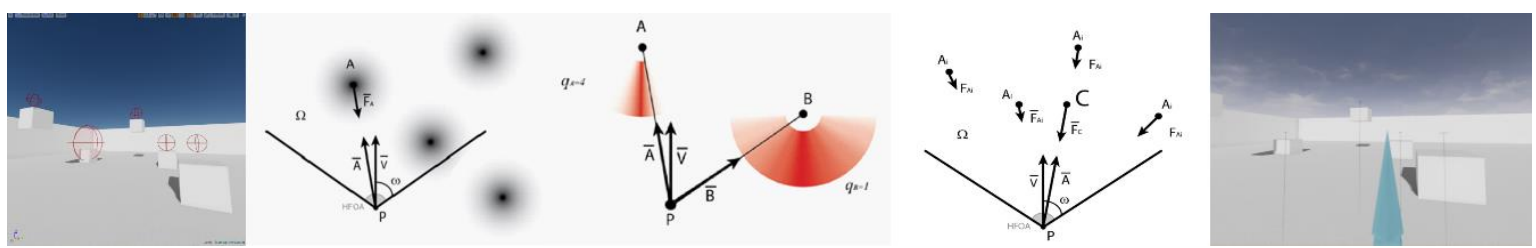

Figure 1. Left to right: Attractors placed on a virtual environment. Field of attention. Parameters for calculation of the attention of attractors. Center of attention. Debug representation of forces and direction to the center of attention

\section{RESULTS}

This new metaphor for the navigation through virtual architectural environments was used to emulate one of the most paradigmatic experiences of architectural walkthrough: La Promenade Architecturale proposed by Le Corbusier for his famous Ville Savoye. (Figure 2). 


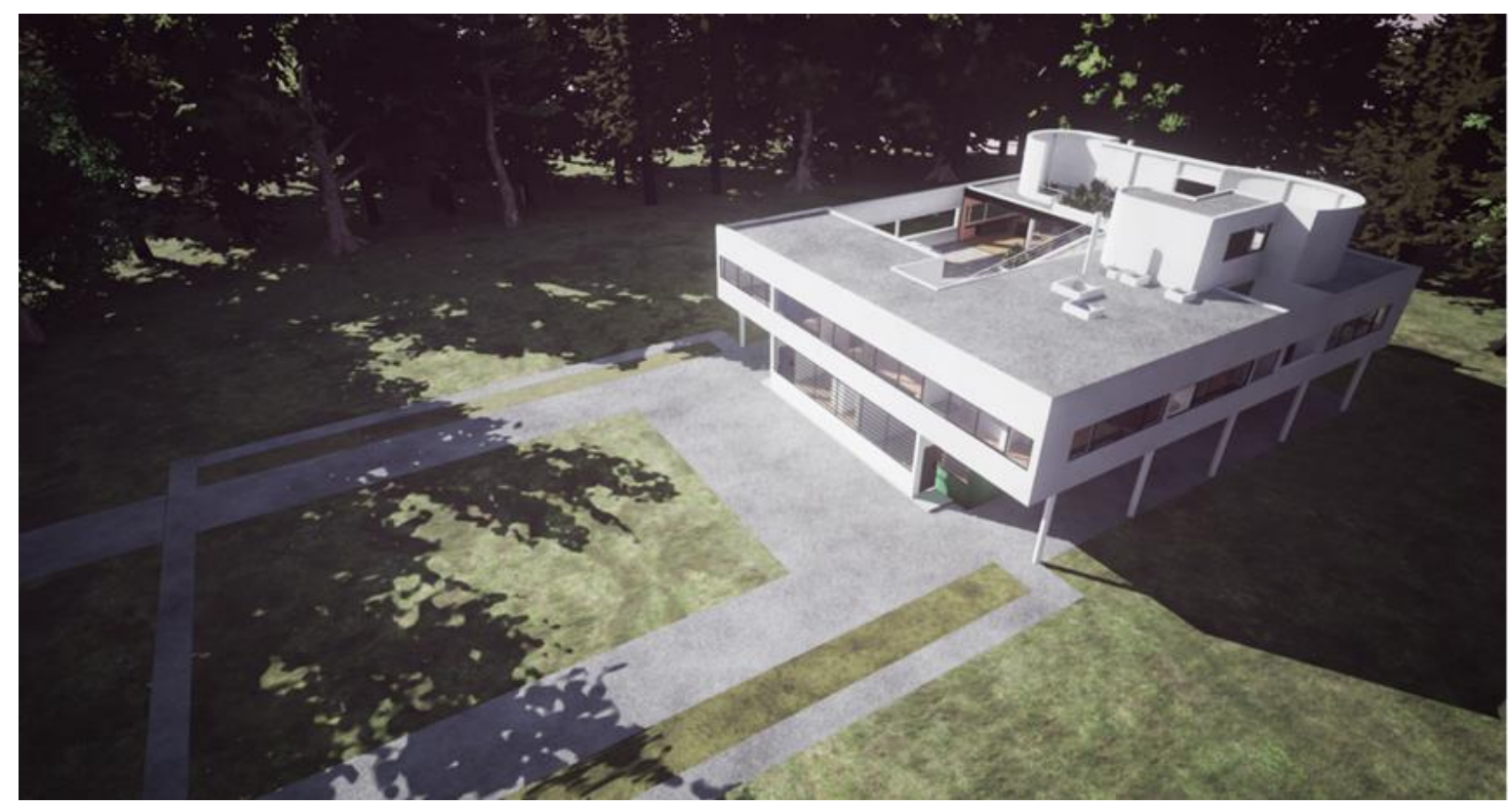

Figure 2. Virtual model of Le Corbusier's Ville Savoye made by the authors for this work

The intended way of perceiving this house is not completely open to the freedom of the visitor, but is mediated by the work of its architect, who defined a priori the sequence of the itinerary. The concept of architectural walk was materialized in an interior ramp that makes possible the continuous perception of living spaces from the main access to the house to the landscape seen from the terrace, establishing different visual and spatial relationships through movement.

The walk is assisted by the attractors that the authors placed inside the building. Attractors are placed in those locations or spaces that the designer of the walk considers that deserve special attention (Figure 3). Objects with special meaning can also be augmented with attractors (Figure 4). By fine-tuning the values related to their intensity, willingness, decay, etc, the authors seek to reproduce the desire of the architect regarding the sequence to follow in the discovery and contemplation of the spaces. While no input from the visitor is detected, Paseante checks the surroundings and evaluates the influence of all attractors in the user's field of view, locates the center of interest and drives the view to focus on this point. Therefore, the user can devolve to Paseante the task to find every interesting part of the building and perform the turns and camera pointing when needed. If the user takes full control of the movement, Paseante, will wait for him or her to stop, then it will visually suggest new places and things to look at in the actual location. In this regard, assisted navigation based on the use of attractors is a valid alternative for space exploration, closer to the human way in which a building can be experienced.

Paseante is well suited to be used in conjunction with natural interaction schemes and devices. The authors are actually making UX test combined with the use of Kinect driven navigation in virtual architectural spaces (Hernandez-Ibáñez, Barneche-Naya, Mihura-López, 2016). 

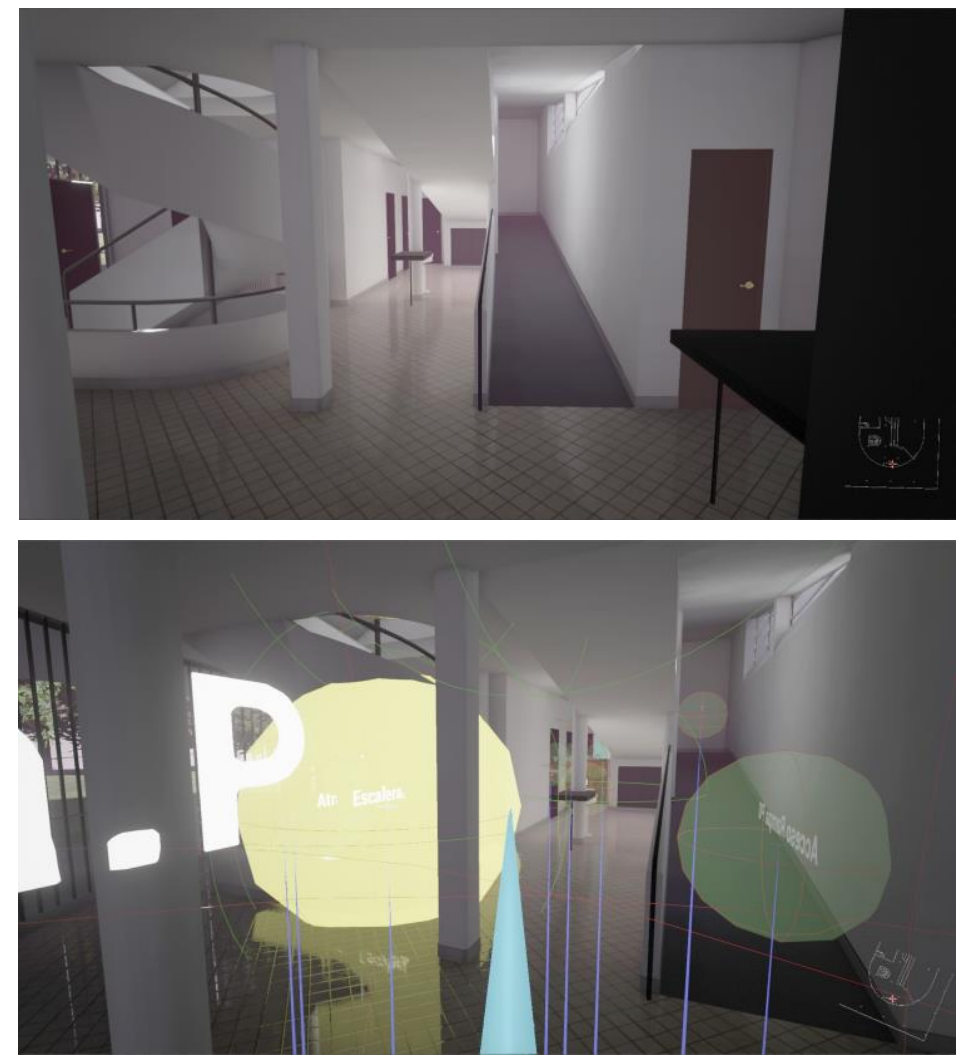

Figure 3. Entrance. Above: Interior space. Below: Attractors located in the areas of interest affecting the view direction
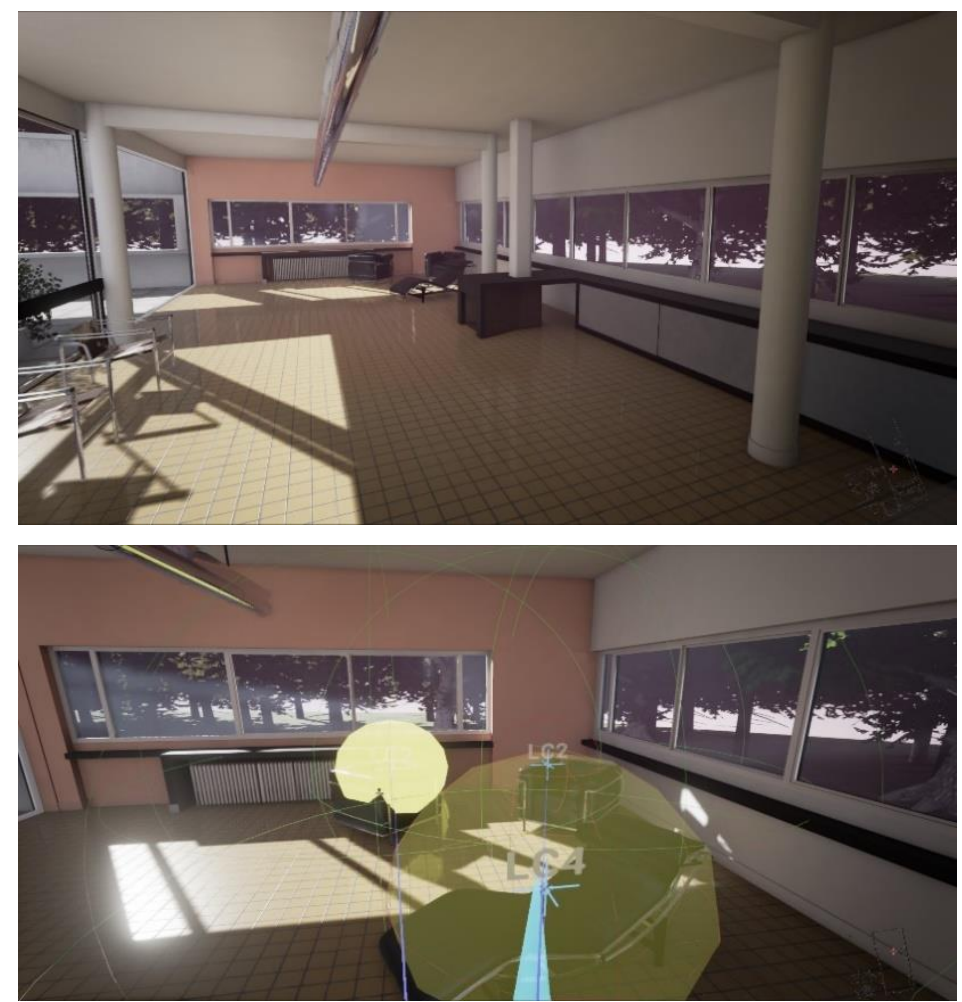

Figure 4. Living-room. Above: View of the space. Below: Attractors located on the objects of interest. Transparency means attention decaying with time 


\section{REFERENCES}

Claessen, M. H., Visser-Meily, J. M., de Rooij, N. K., Postma, A., \& van der Ham, I. J., 2016. A direct comparison of real-world and virtual navigation performance in chronic stroke patients. Journal of the International Neuropsychological Society, 22(4), 467-477.

Cogné, M., Taillade, M., N'Kaoua, B., Tarruella, A., Klinger, E., Larrue, F., ... \& Sorita, E., 2017. The contribution of virtual reality to the diagnosis of spatial navigation disorders and to the study of the role of navigational aids: A systematic literature review. Annals of physical and rehabilitation medicine, 60(3), 164-176.

Foreman, N., Stanton-Fraser, D., Wilson, P. N., Duffy, H., \& Parnell, R., 2005. Transfer of spatial knowledge to a two-level shopping mall in older people, following virtual exploration. Environment and Behavior, 37(2), 275-292.

Gaunet, F., Vidal, M., Kemeny, A., \& Berthoz, A., 2001. Active, passive and snapshot exploration in a virtual environment: influence on scene memory, reorientation and path memory. Cognitive Brain Research, 11(3), 409-420.

Gibson, J., 1979. The Ecological Approach to Visual Perception. Hillsdale, NJ: Lawrence Erlbaum Associates.

Hernandez-Ibáñez, L.A., Barneche-Naya, V., Mihura-López, R., 2016. A comparative study of walkthrough paradigms for virtual environments using Kinect based natural interaction. 22nd International Conference on Virtual System \& Multimedia (VSMM) pp 210-2177. IEEE

LaBerge, D., \& Brown, V., 1989. Theory of attentional operations in shape identification. Psychological review, 96(1), 101.

Lewin, K., 1938. The conceptual representation and the measurement of psychological forces. Duke University. Contributions to Psychological Theory.

Plancher, G., Tirard, A., Gyselinck, V., Nicolas, S., \& Piolino, P., 2012. Using virtual reality to characterize episodic memory profiles in amnestic mild cognitive impairment and Alzheimer's disease: influence of active and passive encoding. Neuropsychologia, 50(5), 592-602.

Posner, M. I., Rafal, R. D., Choate, L. S., \& Vaughan, J., 1985. Inhibition of return: Neural basis and function. Cognitive neuropsychology, 2(3), 211-228.

Raubal, M \& Winter S., 2002. Enriching wayfinding instructions with local landmarks. International conference on geographic information science. 243-259. Springer, Berlin, Heidelberg.

Richardson, A. E., Montello, D. R., \& Hegarty, M., 1999. Spatial knowledge acquisition from maps and from navigation in real and virtual environments. Memory \& cognition, 27(4), 741-750.

Smith, S. P., \& Du'Mont, S., 2009. Measuring the effect of gaming experience on virtual environment navigation tasks. 2009 IEEE Symposium on 3D User Interfaces, pp. 3-10.

Sorrows, M. E., \& Hirtle, S. C., 1999. The nature of landmarks for real and electronic spaces. International Conference on Spatial Information Theory. pp. 37-50. Springer, Berlin, Heidelberg

Waller, D. (2000). Individual differences in spatial learning from computer-simulated environments. Journal of Experimental Psychology: Applied, 6(4), 307. 